\title{
"The reports of my death have been greatly exaggerated": The appraisal of apicoaortic conduit in the transcatheter aortic valve replacement era
}

\author{
Juan A. Crestanello, MD
}

From the Department of Cardiovascular Surgery Mayo Clinic, Rochester, Minn.

Disclosures: Author has nothing to disclose with regard to commercial support.

Received for publication April 11, 2018; accepted for publication April 12, 2018; available ahead of print May 17, 2016.

Address for reprints: Juan A. Crestanello, MD, Department of Cardiovascular Surgery, Mayo Clinic, 200 First St SW, Rochester, MN 55905 (E-mail: crestanello.juan@mayo.edu).

J Thorac Cardiovasc Surg 2018;156:1013-4

$0022-5223 / \$ 36.00$

Copyright (C) 2018 by The American Association for Thoracic Surgery

https://doi.org/10.1016/j.jtcvs.2018.04.058

Patients with aortic stenosis who would be at high or extreme risk if undergoing surgical aortic valve replacement (SAVR) are treated with transcatheter aortic valve replacement (TAVR). Surgical risk determination is based on physiologic and anatomic features. Physiologic features, reflected in the Society of Thoracic Surgeons predicted risk of operative mortality and frailty indices, are mostly driven by age, comorbidities, organ dysfunction, and frailty. ${ }^{1}$ Anatomic features that preclude the safe performance of median sternotomy, aortic cannulation, crossclamp, or aortotomy are among others thoracic artery graft behind the sternum, porcelain aorta, previous radiation, mediastinitis or muscle flaps, and multiple sternotomies. ${ }^{2}$ Before TAVR, patients with anatomic contraindications to SAVR were considered for an apicoaortic conduit (AAC), also known as aortic valve bypass. ${ }^{3}$ Although most such patients are now treated with TAVR, there is still a role for AAC for selected patients with a combination of anatomic contraindications to both TAVR and SAVR. Thus, to paraphrase Mark Twain, the reports of the death of the AAC are greatly exaggerated. For example, an AAC should be considered in patients who (1) do not qualify for TAVR because of risk of coronary occlusion, annular rupture, or perivalvular leak; and (2) have anatomic features that preclude SAVR. AAC placement is not an inconsequential operation, associated as it is with higher morbidity and mortality than either TAVR or SAVR, but it may be the only option in those selected patients. As such, I do not advocate for the performance of AAC in patients who are deemed high risk for physiologic reasons.

In this issue of the Journal, Mantini and colleagues ${ }^{4}$ present their experience with the performance of AAC and the evaluation of aortic and cerebral blood flows at rest. Several lessons can be learn from this article:

1. It is possible to perform this procedure without cardiopulmonary bypass by using a special coring device and apical connector. Similar techniques have been used

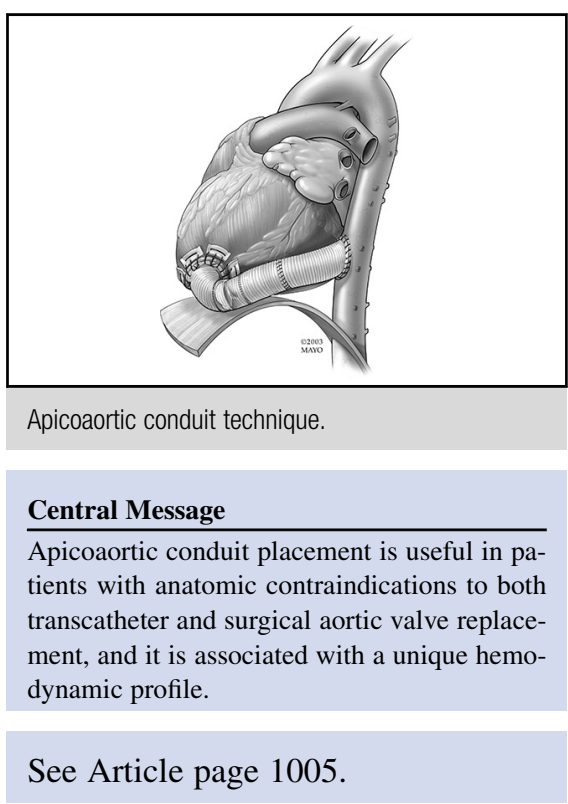

for the off-pump insertion of left ventricular assist devices. ${ }^{5}$ Many surgeons, however, prefer to insert the AAC on pump, without aortic crossclamping, with the heart fibrillating, and without the use of the apical connector (Figure 1).

2. There is a double outlet to the left ventricle: $60 \%$ to $70 \%$ of the stroke volume exits the heart through the AAC, while $30 \%$ to $40 \%$ exits through the native aortic valve.

3. There is a bimodal distribution of flow in the aorta: the flow to the ascending aorta and arch vessels (myocardium, brain, and upper extremities) is provided by the still stenotic native aortic valve, while the flow to the lower extremities and abdominal viscera is provided by the AAC. Less than $10 \%$ of the flow through the AAC flows retrograde into the proximal descending aorta above the level of conduit insertion.

4. After the insertion of AAC, cerebral blood flow at rest is similar to preoperative cerebral blood flow and depends on adequate output through the native aortic valve.

5. After the insertion of the AAC, flow across the native aortic valve decreases with the consequent decrease in the peak aortic velocity. The severity of the native aortic valve stenosis not only is unchanged but likely will progress with time, leading to compromise of flow in the ascending aorta and arch vessels. 


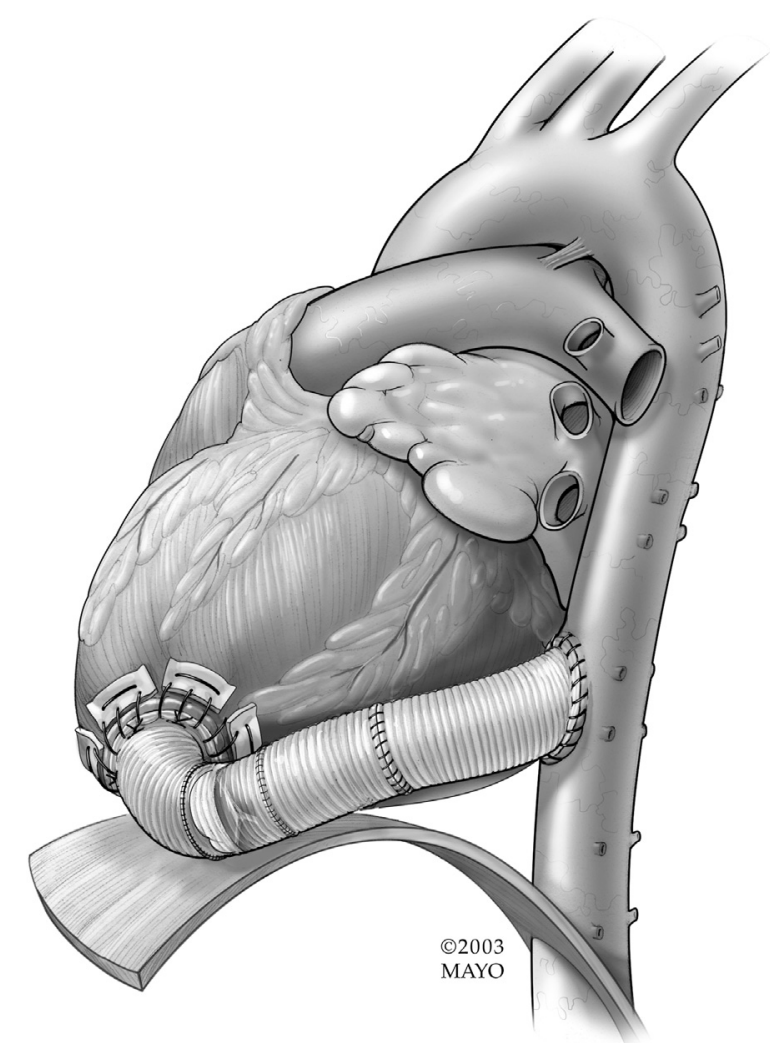

FIGURE 1. Apicoaortic conduit technique: The aortic anastomosis is constructed first. The ventricular anastomosis is then performed with large pledgeted sutures to ensure hemostasis. An apical connector is not used. The conduit valve is located as close as possible to the left ventricular apex. Finally, the ends of the conduits are anastomosed together.

The measurements in the report of Mantini and colleagues ${ }^{4}$ were performed at rest. Several conditions, such as exercise, progression of native aortic valve stenosis, and decreased left ventricular ejection fraction, may alter the contribution of each outlet to the total stroke volume and the distribution of flow in the aorta. ${ }^{6-9}$ For example, during exercise, coronary and systemic vasodilation leads to increased flow demand in the myocardium and lower extremities. Although the output through the AAC will likely increase to provide more flow to the lower extremities, the output through the stenotic aortic valve may not do so, potentially generating myocardial and brain hypoperfusion, unless retrograde flow through the descending aorta into the arch and ascending aorta increases. Progression of the native aortic valve stenosis and worsening of left ventricular function will likely have similar effects, with decreased contribution of the native aortic valve flow to the total stroke volume and increased retrograde flow into the ascending aorta and arch. Flow disturbances have also been described after TAVR and SAVR, but both provide a single source of aortic flow, with the ability to increase cardiac output in response to increased demands. Although TAVR and SAVR improve exercise tolerance, ${ }^{10,11}$ the physiologic limitations associated with a double ventricular outlet and a bimodal aortic flow distribution may limit functional recovery in AAC.

\section{References}

1. Hermiller JB Jr, Yakubov SJ, Reardon MJ, Deeb GM, Adams DH, Afilalo J, et al; CoreValve United States Clinical Investigators. Predicting early and late mortality after transcatheter aortic valve replacement. J Am Coll Cardiol. 2016;68: 343-52.

2. Popma JJ, Adams DH, Reardon MJ, Yakubov SJ, Kleiman NS, Heimansohn D, et al; CoreValve United States Clinical Investigators. Transcatheter aortic valve replacement using a self-expanding bioprosthesis in patients with severe aortic stenosis at extreme risk for surgery. J Am Coll Cardiol. 2014;63: 1972-81.

3. Crestanello JA, Zehr KJ, Daly RC, Orszulak TA, Schaff HV. Is there a role for the left ventricle apical-aortic conduit for acquired aortic stenosis? J Heart Valve Dis. 2004;13:57-62; discussion 62-3.

4. Mantini C, Caulo M, Marinelli D, Chiacchiaretta P, Tartaro A, Cotroneo AR, et al. Aortic valve bypass surgery in severe aortic valve stenosis: insights from cardiac and brain magnetic resonance imaging. J Thorac Cardiovasc Surg. 2018; 156:1005-12.

5. Sun BC, Firstenberg MS, Louis LB, Panza A, Crestanello JA, Sirak J, et al. Placement of long-term implantable ventricular assist devices without the use of cardiopulmonary bypass. J Heart Lung Transplant. 2008;27: 718-21.

6. Balaras E, Cha KS, Griffith BP, Gammie JS. Treatment of aortic stenosis with aortic valve bypass (apicoaortic conduit) surgery: an assessment using computational modeling. J Thorac Cardiovasc Surg. 2009;137:680-7.

7. Lam A, Clement-Guinaudeau S, Padala M, Eisner RL, Thourani V, Vadnais D, et al. Postsurgical hemodynamics of the aortic valve bypass operation evaluated with phase contrast magnetic resonance. J Magn Reson Imaging. 2014;40: 899-905.

8. Benevento E, Djebbari A, Keshavarz-Motamed Z, Cecere R, Kadem L. Hemodynamic changes following aortic valve bypass: a mathematical approach. PLoS One. 2015;10:e123000

9. Kawahito K, Kimura N, Komiya K, Nakamura M, Misawa Y. Blood flow competition after aortic valve bypass: an evaluation using computational fluid dynamics. Interact Cardiovasc Thorac Surg. 2017;24:670-6.

10. Güçlü A, Knaapen P, Harms HJ, Vonk AB, Stooker W, Groepenhoff H, et al. Myocardial efficiency is an important determinant of functional improvement after aortic valve replacement in aortic valve stenosis patients: a combined PET and CMR study. Eur Heart J Cardiovasc Imaging. 2015;16:882-9.

11. Abdul-Jawad Altisent O, Puri R, Regueiro A, Chamandi C, Rodriguez-Gabella T, Del Trigo M, et al. Predictors and association with clinical outcomes of the changes in exercise capacity after transcatheter aortic valve replacement. Circulation. 2017;136:632-43. 